\title{
Myopathy in an Infant with a Fatal Peroxisomal Disorder
}

\author{
Jon Wolff, MD*, William L. Nyhan, MD, PhD*, \\ Henry Powell, MD**, Donna Takahashi, MD***广, \\ Joel Hutzler, PhDף, Amiya K. Hajra, PhD\$, Nabanita S. Datta PhD§, \\ Inderjit Singh, PhD', and Hugo W. Moser, MD'
}

An infant with neonatal adrenoleukodystrophy experienced extreme hypotonia and virtually continuous convulsions at four months of age and died. Light and electron microscopic examination revealed evidence of myopathy and the presence of mitochondrial inclusions. Concentrations of very long-chain fatty acids were elevated in blood and fibroblasts and the oxidation of ${ }^{14} \mathrm{C}$-labeled fatty acids was defective. Urinary pipecolic acid content was increased. Activity of the peroxisomal dihydroxyacetone phosphate acyltransferase, which catalyzes the first step in plasmalogen synthesis, was decreased.

Wolff J, Nyhan WL, Powell H, Takahashi D, Hutzler J, Hajra AK, Datta NS, Singh I, Moser HW. Myopathy in an infant with a fatal peroxisomal disorder. Pediatr Neurol 1986;2:141-6.

\section{Introduction}

Neonatal adrenoleukodystrophy is an autosomal recessive disorder characterized by profound hypotonia and intractable seizures [1]. Hypotonia is severe enough to suggest a diagnosis of primary myopathy. However, histologic studies of muscle have not been reported previously. These patients, as well as those with adrenoleukodystrophy, accumulate very long-chain fatty acids [1-4]. Classic adrenoleukodystrophy is Xlinked; neonatal adrenoleukodystrophy is not.

Although biochemical data was published on 11 patients with neonatal adrenoleukodystrophy, clinical details are available on only 6 patients [5-8]. Hepatomegaly may be present and transaminase levels usually are abnormal. Histologic study demonstrates hepatic fibrosis [1]. Usually there is no clinical evidence of adrenal insufficiency; however, the adrenals have been very small at autopsy $[1,8]$ and histologic examination has revealed extensive cortical atrophy and ballooned cells with ultramicroscopic evidence of lamellar lipid inclusions. The neuropathology was characterized by polymicrogyria as well as extensive demyelination in the cerebral white matter.

Accumulation of very long-chain fatty acids in plasma and cultured fibroblasts is the diagnostic feature of classic X-linked adrenoleukodystrophy $[9,10]$. The levels obtained in neonatal adrenoleukodystrophy were very high $[3,4]$, and elevated concentrations of these fatty acids also were found in the cerebrohepatorenal syndrome of Zellweger and in hyperpipecolic acidemia [4].

We describe an infant with neonatal adrenoleukodystrophy; however, the electron microscopic appearance of the mitochondria in the muscle suggested a myopathy. The concentration of very long-chain fatty acids was relatively high, as were the ratios of $\mathrm{C} 26: 0$ to $\mathrm{C} 22: 0$ acids in plasma and fibroblasts.

\section{Case Report}

A 2-month-old infant (Fig 1) was transported from the neonatal intensive care unit of the Al-Hada Hospital in Saudi Arabia to the University of California San Diego Medical Center because of extreme hypotonia and convulsions. Her mother was a 37-year-old epileptic Saudi Arabian woman who had been treated with phenytoin for 16 years and had received $100 \mathrm{mg}$ twice-a-day during the pregnancy. Birth weight was 2,400 grams. Three older siblings were well. The fourth child, also a girl, had hypotonia and seizures. The clectroencephalogram (EEG) was very abnormal and she was treated with phenobarbital and phenytoin. An extensive investigation in London, including muscle biopsy, did not yield a diagnosis. She died at 4 months of age. There was no apparent consanguinity.

The patient was meconium-stained at birth but none was evident
From the Departments of *Pediatrics and **Pathology; University of California San Diego; La Jolla, CA; ***Department of Pediatrics; AlHada Hospital; Taif, Saudi Arabia; JJohn F. Kennedy Institute; Baltimore, Maryland; FDepartment of Pediatrics; New York University School of Medicine; New York, NY; ${ }^{\$}$ Department of Biological Chemistry; University of Michigan; Ann Arbor, MI; The John F. Kennedy Institute for Handicapped Children; Departments of Neurology and Pediatrics, The Johns Hopkins Medical Institution; Baltimore, MD.
Communications should be addressed to:

Dr. Nyhan; Department of Pediatrics, M-009; University of California San Diego; La Jolla, CA 92093.

Received November 18, 1985; accepted April 1, 1986. 


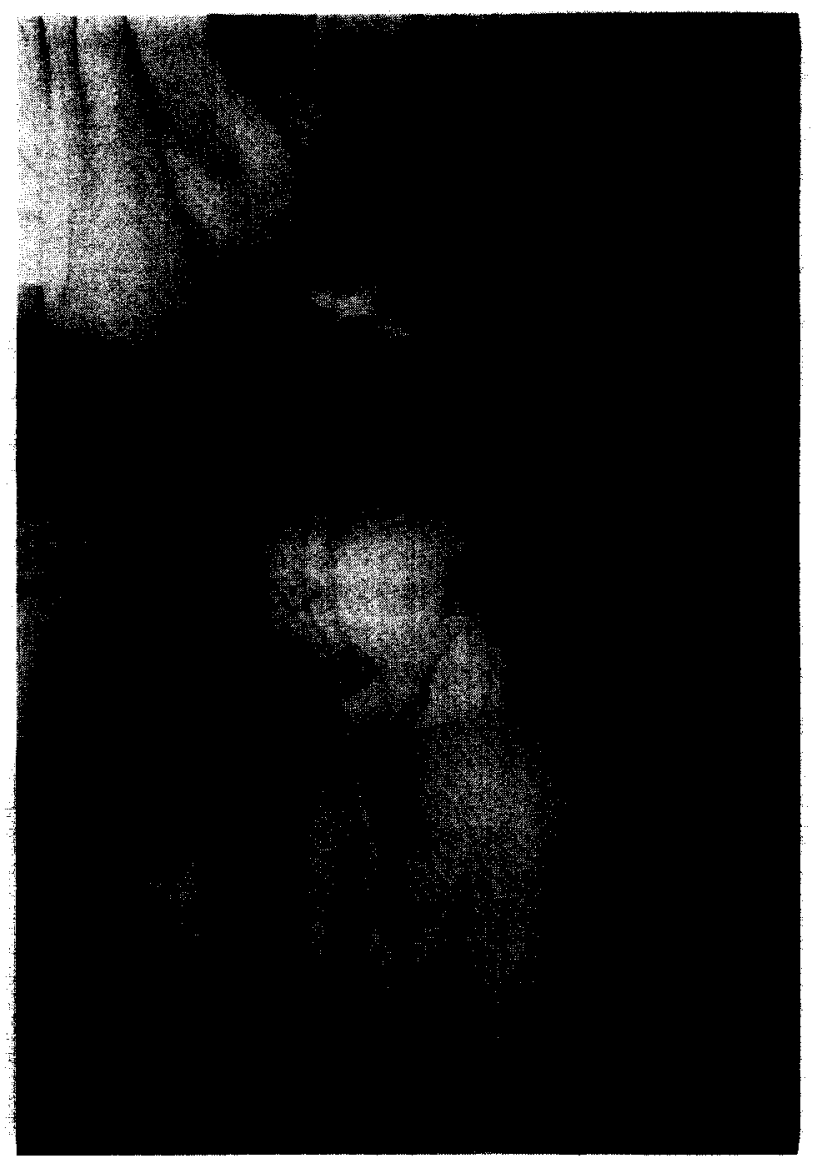

Figure 1. The patient photographed at $31 / 2$ months of age illustrating the hypotonia and the ptosis on the left. below the cords. She cried spontaneously but immediately developed gasping respirations. She was cyanotic and atonic, and was intubated and treated with oxygen and sodium bicarbonate; respirations improved. Apgar scores were 4 at 1 minute and 7 at 5 minutes. Chest roentgenogram revealed a right upper lobe infiltrate and antibiotic therapy was begun. Cultures were negative. A few hours after birth she had a generalized seizure and phenobarbital therapy was initiated. She was fed by nasogastric tube because of swallowing difficulty. At the time of admission she had 2-3 seizures per hour.

Laboratory studies performed prior to transport were normal, including complete blood counts, electrolyte analysis, ammonia and thyroxine levels, and a lumbar puncture. The creatine kinase $(\mathrm{CK})$ was $130 \mathrm{U} / \mathrm{L}$, but a skin infarction on the left thigh caused by an umbilical artery catheter may have caused the elevation. Computed tomography (CT) revealed patchy lucencies in white and gray matter.

Physical examination revealed an extraordinarily hypotonic female infant (Fig 1) who appeared to be having virtually continuous seizures. These were characterized by myoclonic jerks, irregular gasping respirations, and smacking of the lips. Head turning and arm extension were frequent concomitants. Occasionally there were generalized tonic-clonic seizures. The infant had few spontaneous movements, but did withdraw from pain. She had a weak cry, very poor suck, and no grasp or Moro response. Brisk nystagmus alternated from horizontal to vertical. Ptosis was evident on the left. There was evidence of bilateral optic atrophy. There were secondary alveolar ridges in the mouth and a diminished gag reflex. Deep tendon reflexes were absent. The temperature was $37.5^{\circ} \mathrm{C}$, pulse $140 / \mathrm{min}$, and respirations $40 / \mathrm{min}$. The weight was 3,300 grams (below the 5 th percentile); the length was $57 \mathrm{~cm}$ (60th percentile); the head circumference was $36.5 \mathrm{~cm}$ (45th percentile). The necrotic area of the right thigh was healing with increased pigment. Roentgenographic survey of the bones was normal. There were no abnormalities of the patellae. Renal sonogram and voiding cystourethrogram were normal.

The hemoglobin was $9.9 \mathrm{gm} / \mathrm{dl}$, hematocrit 10 , leukocyte count $6,700 / \mathrm{mm}^{3}$ with a normal differential count, and the platelet count was $254,000 / \mathrm{mm}^{3}$. The $\mathrm{pH}$ was $7.44, \mathrm{PCO}_{2} 35$, and $\mathrm{PO}_{2} 106$. The other serum levels were: sodium $137 \mathrm{mEq} / \mathrm{L}$, potassium $4.4 \mathrm{mEq} / \mathrm{L}$,

Table 1. Very long-chain saturated fatty acids in blood plasma

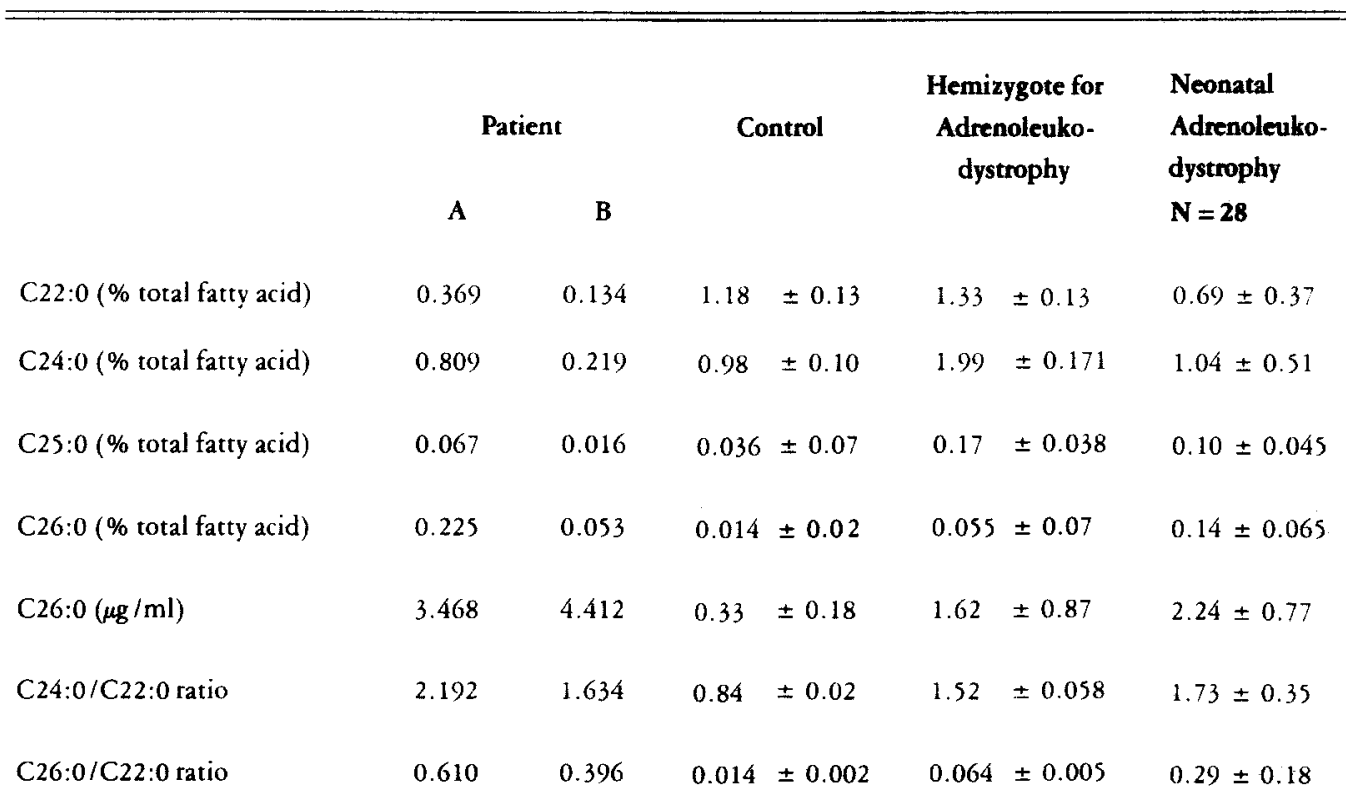

The data for the normal controls and the hemizygotes for adrenoleukodystrophy represent the means \pm standard deviations and were reported $[9,17]$. The neonatal adtenoleukodystrophy data are from an unpublished series of patients [20]. A and B represent two different analyses of the patient. 


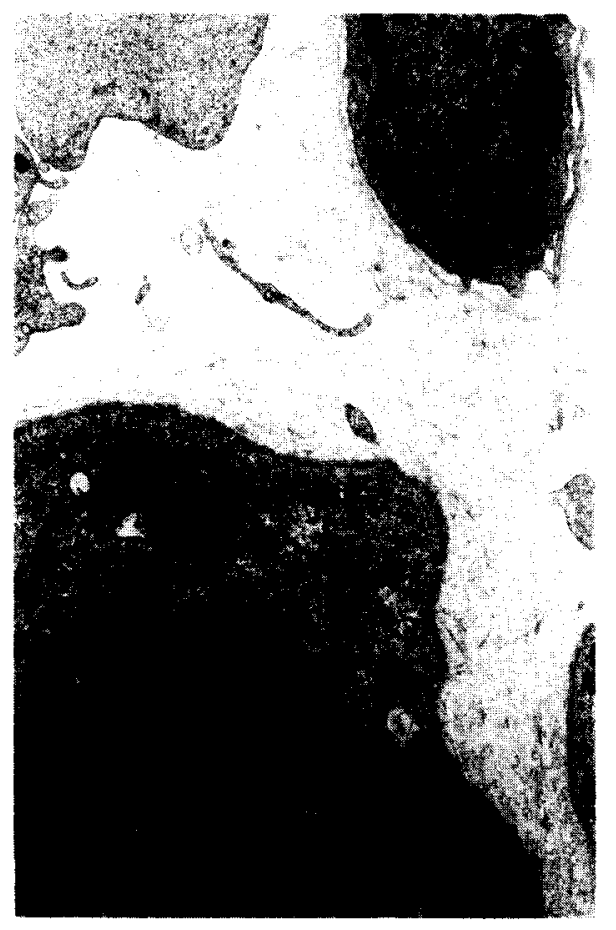

$A$

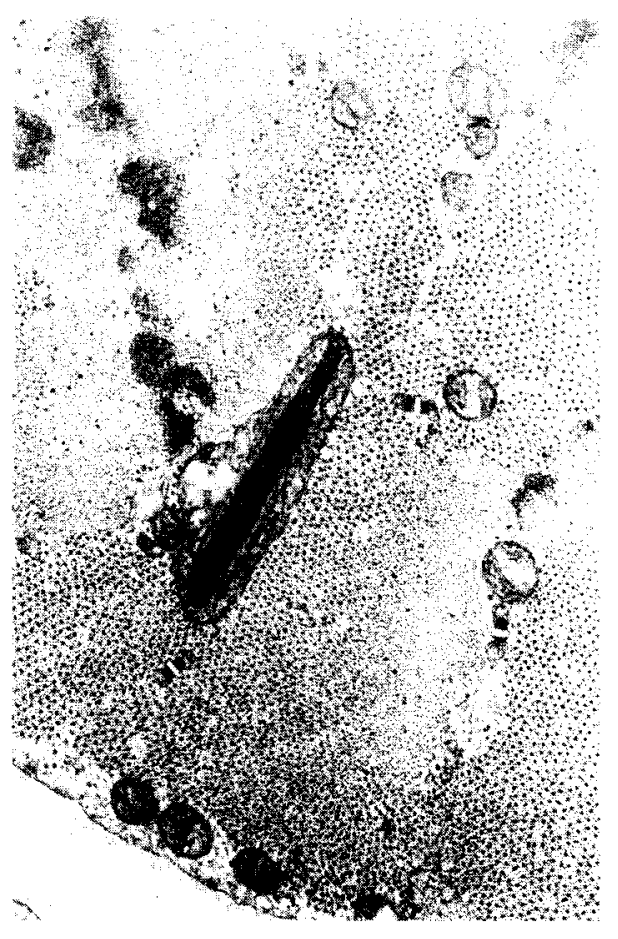

$B$

Figure 2. (A) Electron microscopic examination of $1.0 \mu \mathrm{m}$ thick plastic embedded sections of biopsied muscle stained with toluidine blue reveals nuclear enlargement and accumulations of mitochondria in the subsarcolemmal area. Some mitochondria were enlarged and an accasional dumbbell-shaped mitochondrion was visible. (B) Paracrystalline inclusion in mitochondrion.

bicarbonate $25 \mathrm{mEq} / \mathrm{L}$, chloride $105 \mathrm{mEq} / \mathrm{L}$, urea nitrogen $6 \mathrm{mg} / \mathrm{dl}$, creatinine $0.3 \mathrm{mg} / \mathrm{dl}$, glucose $70 \mathrm{mg} / \mathrm{dl}$, calcium $10 \mathrm{mg} / \mathrm{dl}$, and total protein $5.4 \mathrm{gm} / \mathrm{dl}$. The plasma free carnitine was $86.6 \mu \mathrm{mol} / \mathrm{L}$ and the esterified fraction was $1.4 \mu \mathrm{m} / \mathrm{L}$. The $\mathrm{CK}$ was $114 \mathrm{U} / \mathrm{L}$, aldolase $12.3 \mathrm{U} / \mathrm{L}, \mathrm{SGPT} 100 \mathrm{U} / \mathrm{L}$, and SGOT $221 \mathrm{U} / \mathrm{L}$. The cerebrospinal fluid concentration of protein was $72 \mathrm{mg} / \mathrm{dl}$.

The EEG revealed epileptiform abnormalities over the parietotemporal area. Brainstem auditory evoked potentials were normal on left-sided stimulation and absent on the right, suggestive of ear disease on that side, but no clinical manifestation was found. Cranial CT revealed evidence of extensive white matter disease and some generalized atrophy. Electromyogram (EMG) demonstrated fibrillation potentials in both deltoids, right biceps, left hamstring, and vastus lateralis. The right ulnar motor response was of normal amplitude and distal latency. Nerve conduction velocities and repetitive nerve stimulation were normal. Muscle biopsy was examined by light and electron microscopy. There was histologic evidence of fiber size variation and many rounded, atrophic fibers. Accumulations of mitochondria in subsarcolemmal areas were seen on electron microscopy (Fig 2). Shapes and sizes varied and paracrystalline mitochondrial inclusions were found. These inclusions, however, are nonspecific and may be seen in a variety of muscle disorders. Abundant muscle glycogen was present. Small intramuscular nerves appeared to have axonal degeneration, consisting of axonal swelling, increased intra-axonal organelles, and drop-out of some axons. The myopathic changes and axonal degeneration observed in this patient are consistent with a diagnosis of chronic neuropathy with associated myopathy. Liver biopsy revealed nonspecific inflammatory changes and mild periportal fibrosis. Prussian blue stain for iron was negative. Electron microscopic examination revealed normal mitochondria, an absence of peroxisomes, and conspicuous bundles of intermediate filaments. The brain was biopsied and increased amounts of lipofuscin pigment were seen in the neurons, but unfortunately white matter was not present in the specimen. Examination of the gray matter revealed no typical cellular inclusions of adrenoleukodystrophy.

Effort was made to control the seizures but despite continued therapy with clonazepam, phenobarbital, and phenytoin and documentation of excellent therapeutic levels in the blood, little changed in the pattern of seizures. An intercurrent urinary tract infection was responsive to antibiotic treatment, and renal sonogram and voiding cystourethrogram were normal. She developed a left otitis media and right upper lobe pneumonia which also responded to antibiotic therapy.

A prolonged fast resulted in hypoglycemia. A blood glucose of 38 $\mathrm{mg} / \mathrm{dl}$ at 16 hours was observed. The concentration of glucose rose to $90 \mathrm{mg} / \mathrm{dl}$ after glucagon $(0.5 \mathrm{mg}$. IM). These observations indicated that gluconeogenesis was normal but adrenal function might have been impaired. Blood was tested for long-chain, saturated fatty acids. The blood concentration of cortisol was $<2.5 \mu \mathrm{g} / \mathrm{dl}$, but rose to 85.2 $\mu \mathrm{g} / \mathrm{dl}$ after 6 , twice-a-day injections of $\mathrm{ACTH}$. Dietary attempts to limit the intake of long-chain fatty acids were not successful because of the development of diarrhea. Similarly, carnitine therapy was not effective. At 4 months of age the patient returned to Saudi Arabia where she died shortly thereafter.

\section{Methods}

Cell culture of fibroblasts was obtained following skin biopsy. Cells were grown at $37^{\circ} \mathrm{C}$. in Eagle's minimum essential medium containing fetal calf serum. Harvesting of the cells, extraction of lipids from fibroblasts and plasma, and purification and assay of fatty acid methyl esters were performed as described previously [3,4] using a system of capillary gas-liquid chromatography for the quantitation of very long-chain fatty acids. Dihydroxyacetone phosphate acyltransferase was assayed in whole fibroblast homogenates by measuring the amount of labeled lipid formed from ${ }^{32} \mathrm{P}$-dihydroxyacetone phosphate as described previously $[11,12]$. 
Table 2. Very long-chain saturated fatty acids in cultured fibroblasts

\begin{tabular}{|c|c|c|c|c|}
\hline & Patient & Control & $\begin{array}{l}\text { Hemizygous for } \\
\text { Adrenoleukodys- } \\
\text { trophy }\end{array}$ & $\begin{array}{c}\text { Neonatal } \\
\text { Adrenoleukodys- } \\
\text { trophy } \\
\mathbf{N}=25\end{array}$ \\
\hline $\mathrm{C} 22: 0$ ( $\mu \mathrm{g} / \mathrm{mg}$ protein) & 0.270 & $0.99 \pm 0.44$ & $0.59 \pm 0.13$ & $0.49 \pm 0.22$ \\
\hline $\mathrm{C} 26.0$ ( $\mu \mathrm{g} / \mathrm{mg}$ protein) & 0.474 & $0.066 \pm 0.35$ & $0.45 \pm 0.05$ & $0.39 \pm 0.16$ \\
\hline C26:1 ( $\mu \mathrm{g} / \mathrm{mg}$ protein) & 0.73 & $0.079 \pm 0.066$ & $0.21 \pm 0.08$ & $0.68 \pm 0.47$ \\
\hline $\mathrm{C} 26: 0 / \mathrm{C} 22: 0$ ratio & 1.756 & $0.064 \pm 0.019$ & $0.76 \pm 0.09$ & $0.88 \pm 0.41$ \\
\hline
\end{tabular}

The mean values for neonatal adrenoleukodystrophy are from an unpublished series [20]. Some of the control and X-linked data have been reported [3], while others represent unpublished data [20].

\section{Results}

The concentrations of very long-chain saturated fatty acids in the plasma of the patient are shown in Table 1. The values were markedly elevated. The concentrations of C26:0 were considerably greater than those of children hemizygous for adrenoleukodystophy [9] and 10 times greater than the control mean. In a series of patients with neonatal adrenoleukodystrophy the mean was $2.24 \pm 0.77[4,20]$. The ratios of C24:0 to $\mathrm{C} 22: 0$ and $\mathrm{C} 26: 0$ to $\mathrm{C} 22: 0$ were both markedly elevated.

The data for cultured fibroblasts are presented in Table 2 . The concentration of C22:0 acid was relatively low while that of $C 26: 0$ was 6.5 times the control mean. The ratio of $\mathrm{C} 26: 0$ to $\mathrm{C22:0}$ not only exceeded the control ratio, but also was more than twice the value obtained in fibroblasts from adrenoleukodystrophy hemizygotes. In a series of patients with neonatal adrenoleukodystrophy the mean concentration of C26:0 in fibroblasts was $0.39 \mu \mathrm{g} / \mathrm{mg}$ protein \pm 0.16 , a level similar to that of $0.474 \mu \mathrm{g} / \mathrm{mg}$ protein, obtained in the patient. The concentration of $\mathrm{C} 26: 1$ in the patient's fibroblasts was $0.73 \mu \mathrm{g} / \mathrm{mg}$ protein. This value is similar to those found in neonatal adrenoleukodystrophy (mean value of 0.68 ), and in the Zellweger syndrome [4], in which the mean value was 1.33. The concentration of pipecolic acid in the urine is listed in Table 3. (Plasma was no longer available). The markedly elevated concentration was $1.94 \mu \mathrm{mol} / \mathrm{mg}$ creatinine; a patient with hyperpipecolic acidemia had a value of $1.92 \mu \mathrm{mol} / \mathrm{mg}$ creatinine, and also had a distinct elevation of the plasma level of pipecolic acid to $74.6 \mathrm{nmol} / \mathrm{ml}$; the level of the control group was $1-2$ $\mathrm{nmol} / \mathrm{ml}$. Healthy individuals have very low levels of pipecolic acid in body fluids [13].

The oxidation of ${ }^{14} \mathrm{C}$-labeled fatty acids was studied in fibroblests as described by Singh et al. [14] (Table 4).
Table 3. Urinary concentmation of pipecolic acid

\begin{tabular}{lcc}
\hline \hline & \multicolumn{2}{c}{ Pipecolic Acid } \\
\cline { 2 - 3 } & nmole/ml mmole/ms crentinine \\
Patient & 155.2 & 1.94 \\
$\begin{array}{l}\text { Patient with } \\
\text { pipecolic acidemia }\end{array}$ & 230.8 & 1.92 \\
\hline
\end{tabular}

The oxidation of palmitic acid was normal. The oxidation of lignoceric acid (C24) was 39\% of the control. The use of the ratio of $\mathrm{C} 16 / \mathrm{C} 24$ reduces variation in different sets of fibroblasts assayed. The value in the patient was 2.8 times control.

Table 5 lists data on the activity of dihydroxyacetone phosphate acyltransferase, the first enzyme of the metabolic pathway for the biosynthesis of the glycerol-

Table 4. ( $\left.{ }^{14} \mathrm{C}\right) \mathrm{CO}_{2}$ release from $(1-14 \mathrm{C})$ palmitic and $(1-14 \mathrm{C})$

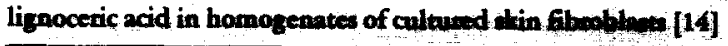

\begin{tabular}{lccc}
\hline & C16 & C24 & C16/C24 \\
& \multicolumn{3}{c}{ Cpm/mg protein } \\
& 14200 & 213 & 67 \\
Patient & 10700 & 129 & 83 \\
Zellweger & 11000 & 204 & 54 \\
$\begin{array}{l}\text { X-linked adrenoleuko- } \\
\text { dystrophy }\end{array}$ & & & \\
Control & 13000 & 545 & 24 \\
\hline
\end{tabular}


Table 5. Activity of dihydroxyacetone phosphate acyltransferase

\begin{tabular}{lc}
\hline \hline & $\begin{array}{c}\text { Activity } \\
\mu \mathrm{mol} / \mathrm{min} / \mathrm{mg} \text { protein } \\
\text { Patient }\end{array}$ \\
Zellweger & 0.06 \\
Neonatal adrenoleukodystrophy & 0.02 \\
Controls & $0.03-0.06$ \\
& $0.23-0.35$ \\
\hline
\end{tabular}

ether lipids and plasmalogen. Cultured fibroblasts derived from the patient approximated $20 \%$ of control values. Similar values were observed in the Zellweger and neonatal adrenoleukodystrophy syndromes $[11,15]$.

\section{Discussion}

The clinical phenotype of this patient was typical, or possibly more severe than that described in neonatal adrenoleukodystrophy [1,5-8]. Extreme hypotonia, present at birth, necessitated endotracheal intubation, resuscitation in the delivery room, and feeding by nasogastric tube. Deep tendon reflexes could not be obtained. The intractable seizure disorder began within hours of birth. Myoclonic and generalized tonic-clonic seizures were virtually continuous. During the few months of her life she had no psychomotor development. In addition she had none of the dysmorphic features seen in the Zellweger syndrome.

The elevated plasma concentrations of long-chain fatty acids indicated that this patient had a peroxisomal disorder. These subcellular organelles contain the system for the hepatic oxidation of very long-chain fatty acids [16]. Accumulations of very long-chain fatty acids in the neonatal period have been found consistently in neonatal adrenoleukodystrophy and Zellweger syndromes $[1,2,4,17]$. Elevated concentrations of very long-chain fatty acids also have been found in two of three patients with pipecolic acidemia; normal concentrations were found in the third [4].

The biochemical characteristics of this patient were documented thoroughly. The ratio of $\mathrm{C} 26 / \mathrm{C} 22$ in fibroblasts and the concentrations of $\mathrm{C} 26: 1$ were elevated. The elevated level of pipecolic acid in the urine was consistent with previous observations of pipecolic acidemia and Zellweger syndrome. The data on the release of ${ }^{14} \mathrm{CO}_{2}$ from ${ }^{14} \mathrm{C}$-labeled palmitic and lignoceric acids revealed defective oxidation of very long-chain fatty acids. Similar results on fatty acid oxidation were obtained in adrenoleukodystrophy, neonatal adrenoleukodystrophy, and Zellweger syndrome $[11,15,17-21]$. The peroxisomal enzyme, dihydroxyacetone phosphate acyltransferase, which catalyzes the first step in plasmalogen synthesis, was reported to be defective in Zellweger syndrome [22-24]. It is also defective in neonatal adrenoleukodystrophy, but is normal in X-linked adrenoleukodystrophy. This peroxisomal activity also was markedly defective in our patient.

Hepatic peroxisomes were not identifiable on electron microscopy in our patient. In Zellweger syndrome, peroxisomes are absent or very small and irregularly shaped [24]. The situation is not clear in neonatal adrenoleukodystrophy, but absence of hepatic peroxisomes has been reported in this condition [25]. In contrast, hepatic peroxisomes are present in hyperpipecolic acidemia which suggests that this patient did not have the disease [26]; however, the absence of a finding is not definitive proof. Until the molecular defects in these conditions have been better defined, clinical phenotype must be used to distinguish among these three disorders of young infants in which very long-chain fatty acids accumulate.

Other laboratory findings in our patient also were only suggestive of the diagnosis. Hepatic fibrosis is an integral component of neonatal adrenoleukodystrophy. Elevation of serum transaminases and other enzymes [1] in an infant with extreme hypotonia and convulsions could serve as an alerting signal to the diagnosis. Mitochondrial morphologic abnormalities in the liver are seen in Zellweger syndrome [18] but our patient's mitochondria in the liver were normal in shape.

In our patient, the development of hypoglycemia during fasting in the presence of a normal response to glucagon suggested adrenal hypofunction; however, the response to ACTH was normal. Signs of adrenal insufficiency are usually absent in neonatal adrenoleukodystrophy, and a normal cortisol response to ACTH was observed in one patient in whom the diagnosis was documented at autopsy [1]. The term neonatal adrenoleukodystrophy may be a misnomer. Although they are involved histologically, the adrenals are much less important than other organs in the phenotype.

CT scan, even in early infancy, revealed extensive disease of the white matter in our patient. Although this was reported in neonatal adrenoleukodystrophy [7], CT scan also was reported to be normal or to show minimal abnormalities [1]. The brainstem auditory evoked potentials in our patient revealed no response on the right side, while the response on the left was normal. She had had no infections prior to the test and there was no evidence of auditory disease. Asymmetric abnormality in the brainstem auditory evoked response has been reported in adrenoleukodystrophy [27]. Also, patients with neonatal adrenoleukodystrophy have inclusions in macrophages of the white matter. The absence of these characteristic inclusions in a small sample of biopsied gray matter does not exclude the diagnosis.

Muscle changes in the patient were of interest and 
have not been described previously in either neonatal adrenoleukodystrophy or in Zellweger syndrome. The mitochondrial inclusions, evidence of myopathy, and neurogenic muscular atrophy, are consistent with the profound hypotonia displayed by the patient. Conversely, hypotonia is characteristic of neonatal adrenoleukodystrophy and may be a uniform characteristic of this disorder. Mitochondrial abnormalities in the liver were reported in some but not all patients with the Zellweger syndrome $[28,29]$ but information on muscle is not available.

This work was supported in part by United States Public Health Service grants No. HD4608 and No. HD10981 from the National Institute of Child Health and Human Development; NIH-NRSA, AM07318, National Institutes of Health; Bethesda, Maryland; General Clinical Research Center grant RR-00827 from the Division of Research Resources; National Institutes of Health; Bethesda, Maryland.

\section{References}

[1] Jaffe R, Crumrine P, Hasida Y, Moser HW. Neonatal adrenoleukodystrophy: Clinical, pathological and biochemical delineation of a syndrome affecting both males and females. Am J Pathol 1982;108:100-11.

[2] Brown FR III, McAdams AJ, Cummins JW, et al. Cerebrohepato-renal (Zellweger) syndrome and neonatal adrenoleukodystrophy: Similarities in phenotype and accumulation of very long chain fatty acids. Johns Hopkins Med J 1982; 151:344-61.

[3] Moser HW, Moser AB, Kawamura N, et al. Adrenoleukodystrophy: Studies of the phenotype, genetics and biochemistry. Johns Hopkins Med J 1980;147:217-24.

[4] Moser AB, Singh I, Brown F III, et al. The cerebro-hepatorenal (Zellweger) syndrome: Increased levels and impaired degradation of very large chain fatty acids and their use in prenatal diagnosis. N Engl J Med 1984;310:1141-6.

[5] Benke PJ, Reyes PF, Parker JC. New form of adrenoleukodystrophy. Hum Genet 1981;58:204-8.

[6] Haas JE, Farrell DF, Johnson ES. Adrenoleukodystrophy variant in a female. Lab Invest $1981 ; 44$ (1):3P.

[7] Mobley WC, White CL, Tennekoon G, et al. Neonatal adrenoleukodystrophy. Ann Neurol 1982;12:204-5.

[8] Ulrich J, Hershkowitz N, Heitz P, Sigrist T, Baerlocher P. Adrenoleukodystrophy. Preliminary report of a connatal case: Light and electron microscopical, immunohistochemical and biochemical findings. Acta Neuropathol 1978;43:77-83.

[9] Moser HW, Moser AB, Frayer $\mathrm{KK}$, et al. Adrenoleukodystrophy: Increased plasma content of saturated very long chain acids. Neurology 1981;31:1241-9.

[10] Ropers H-H, Burmeister P, von Petrykowski W, Schnider F. Leukodystrophy, skin hyperpigmentation, and adrenal atrophy: Siemerling-Creutzfeldt disease: Transmission through several generations in two families. Am J Hum Genet 1975;27:547-53.

[11] Datta NS, Wilson GN, Hajra AK. Deficiency of enzymes catalyzing the biosynthesis of glycerol-ether lipids in Zellweger syndrome: A new category of metabolic disease involving the absence of peroxisomes. N Engl J Med 1984;311:1080-3.

[12] Jones CL, Hajra AK. Properties of guinea pig liver peroxisomal dihydroxyacetone phosphate acyltransferase. J Biol Chem 1980;255:8289-95.

[13] Hutzler J, Dancis J. The determination of pipecolic acid Method and results of hospital survey. Clin Chim Acta 1983; 128:75.82

[14] Singh I, Moser AB, Moser HW, Kishimoto $Y$. Adrenoleukodystrophy: Impaired oxidation of very long chain fatty acids in white blood cells, cultured skin fibroblasts, and amniocytes. Pediatr Res 1984;18:286-90.

[15] Hajra AK, Datta NS, Jackson LJ, et al. Prenatal diagnosis of Zellweger cerebrohepatorenal syndrome. N Engl J Med 1985; 312:445-6.

[16] Kawamura N, Moawe HW, Kishimoto Y. Very long chain fatty acid oxidation in rat liver. Biochem Biophys Res Commun 1981;99:1216-25.

[17] Moser HW, Moser AB, Singh I, O'Neill BP. Adrenoleukodystrophy. Survey of 303 cases: Biochemistry, diagnosis and therapy. Ann Neurol; In press.

[18] Schutgens RBH, Romeyn GJ, Wanders RJA, v d Bosch $H$, Schrakamp G, Heymans HSA. Deficiency of acyl-CoA: Dihydroxyacetone phosphate acyltransferase in patients with Zellweger (cerebro-hepato-renal) syndrome. Biochem Biophys Res Commun 1982;120:179-84

[19] Kelley RI, Datta NS, Dobyns WB, et al. Neonatal adrenoleukodystrophy: New cases, biochemical studies and differentiation from Zellweger and related peroxisomal polydystrophy syndromes. Am J Med Genet 1986;23:869-901.

[20] Moser HW. Unpublished data.

[21] Singh I, Moser $H W$, Moser AB, Kishimoto $Y$. Adrenoleukodystrophy: Impaired oxidation of long chain fatty acids in cultured skin fibroblasts and adrenal cortex. Biochem Biophys Res Commun 1981;102:1233-9.

[22] Heymans HSA, v d Bosch H, Schurgens RBH, et al. Deficiency of plasmalogens in the cerebro-hepato-renal (Zellweger) syndrome. Eur J Pediatr 1984;142:16-20.

[23] Schutgens RBH, Heymans HSA, Wanders RJA, v d Bosch $H$, Schrakamp G. Prenatal detection of Zellweger syndrome. Lancet 1984;2:1339-40.

[24] Versmold HT, Bremer XJ, Herzog V, et al. A metabolic disorder similar to Zellweger syndrome with hepatic acatalasia and absence of peroxisomes, altered content and redox state of cytochromes, and infantile cirrhosis with hemosiderosis. Eur J Pediatr 1977:124:261-75

[25] Partin JS, McAdams JA. Absence of hepatic peroxisomes in neonatal onset adrenoleukodystrophy. Pediatr Res 1982;17:294A.

[26] Burton BK, Reed SP, Remy WT. Hyperpipecolic acidemia: Clinical and biochemical observations in two male siblings. J Pediatr 1981;99:729-34.

[27] Black JA, Fariello RG, Chun RW. Brainstem auditory evoked response in adrenoleukodystrophy. Ann Neurol 1979; 6:269-70.

[28] Goldfisher S, Moore CL, Johnson AB, et al. Peroxisomal and mitochondrial defects in the cerebro-hepato-renal syndrome. Science $1973 ; 82: 62-4$

[29] Goldfischer S, Moore CL, Johnson AB, et al. Mitochondrial dysfunction in the cerebro-hepato-renal syndrome. Am J Pathol 1972;66:43A 